our responsibilities. (In passing I would deplore the antithesis which is sometimes fabricated between science and compassion. It was no professional social reformer, but the great Virchow, who said that doctors were the natural advocates of the poor.) Passionately though I myself believe in the value of a good tradition, we seem to be living in an age when such an appeal is insufficient. Despite the dangers of prediction, I suggest that it is the future of our profession, rather than its past, which compels us towards altruism. We can now do more for our patients than ever before, and we still stand high in public esteem, as tested in the current fashion by "attitude surveys." Justified public trust is the only solid base for the future statusand I do not forget material status-of our great profession. We are going through a troubled time, but if we hold to professional standards, we shall certainly come through it; otherwise I believe we shall be courting the very dangers of subservience which we are seeking by short-term expedients to avoid.

\section{Conclusion}

Having begun with a Latin title, may I end with a Latin tag ? It seems to me to express, with the economy characteristic of that language, a good deal of what I have just been saying. Speaking of the disorders which followed the death of Vitellius, Tacitus says "Inter turbas et discordias pessimo cuique plurima vis, pax et quies bonis artibus indigent." Or, in the Loeb translation, "In times of violence and civil strife the worst men have the greatest power; peace and quiet call for honest arts."

\section{References}

${ }^{1}$ Fox, T, Lancet, 1965, 2, 801.

Illich, I, Medical Nemesis. London, Calder and Boyars, 1975.

${ }^{3}$ Gallagher, E B, Social Science and Medicine, 1976, 10, 207.
4 Parsons, T, Health and Society, 1975, 53, 257.

'Gerson, E M, Social Science and Medicine, 1976, 10, 219.

'Tuckett, D, An Introduction to Medical Sociology. London, Tavistock Publications, 1976.

- Cochrane, A L, Effectiveness and Efficiency: Random Reflections on Health Services. London, Nuffield Provincial Hospitals Trust/Oxford University Press, 1972

${ }^{8}$ McKeown, T, The Role of Medicine: Dream, Mirage or Nemesis. London, Nuffield Provincial Hospitals Trust, 1976.

${ }^{9}$ Lever, A F, Lancet, 1977, 1, 352.

${ }^{10}$ Social Science Research Council, Health and Health Policy-Priorities for Research (report of an advisory panel to the Research Initiatives Board). London, 1977.

${ }^{11}$ Black, D A K, in Research and Medical Practice-their Interaction, ed G W Wolstenholme and M O'Connor, p 169. Amsterdam, Elsevier, 1976 .

12 Williams, A, British Medical Bulletin, 1974, 30, 252.

${ }^{13}$ Davies, D H, Modern Medicine-a Doctor's Dissent. London, AbelardSchuman, 1977.

14 McLachlan, G, A Question of Quality? London, Nuffield Provincial Hospitals Trust Oxford University Press, 1976.

${ }^{15}$ Drummond, M F (1977), Economic Evaluation in Health Care-a Guide for Non-economists. To be published in 1978.

${ }^{16}$ Havard, C W H, and Pearson, R M, Prescriber's fournal, 1977, 17, 94.

' Klarman, H E, Francis, J O' S, and Rosenthal, G D, Medical Care, 1968 , 6, 48.

${ }^{18}$ Maxwell, R, Health Care-the Growing Dilemma, 2nd edn. New York, McKinsey, 1976.

19 Klarman, H E, Daedalus, 1977, 1, 215.

${ }^{20}$ Eisenberg, L, Daedalus, 1977, 1, 235.

21 Webster, C, The Great Instauration-Science, Medicine and Reform, 1626-1660. London, Duckworth, 1975.

${ }^{22}$ Keele, K D, William Harvey: the Man, the Physician and the Scientist. London, Nelson, 1965.

${ }^{23}$ Pickering, G W, Proceedings of the Royal Society of Medicine, 1977, 70, 16.

(Accepted 31 August 1977)

\title{
Prostaglandin-induced abortion and outcome of subsequent pregnancies: a prospective controlled study
}

\author{
I Z MACKENZIE， KEITH HILLIER
}

British Medical fournal, 1977, 2, 1114-1117

\section{Summary}

We analysed a prospective series of 204 pregnancies occurring in 168 women after a prostaglandin-induced abortion. The mean ( standard error of mean) interval between abortion and first subsequent conception was 10.4 0.6 months; no patient reported secondary subfertility.

Fifty-five of the subsequent pregnancies were terminated, 23 during the second trimester, again using prostaglandins. Of the 149 pregnancies not terminated, 127 were delivered at term, and 19 spontaneously aborted, seven during the second trimester; there was one missed

Nuffield Department of Obstetrics and Gynaecology, University of Oxford, John Radcliffe Hospital, Headington, Oxford OX3 9 DU I Z MACKENZIE, MRCOG, clinical lecturer

Pharmacology Group, Medical Faculty, University of Southampton, Southampton SO9 $5 \mathrm{NH}$

KEITH HILLIER, PHD, senior lecturer abortion and two ectopic pregnancies. Morbidity in the 127 term pregnancies was infrequent; spontaneous preterm labour occurred in three patients, and four singleton infants weighed less than $2500 \mathrm{~g}$ at birth. There was no apparent association between morbidity in the subsequent pregnancies and the period of gestation at the time of the previous abortion, route of prostaglandin administration, or need for post-abortion curettage.

The results obtained overall were very similar to a control group of 612 women consecutively admitted for delivery or abortion to the Oxford obstetrical and gynaecological units. There was, however, an increased incidence of spontaneous abortion and placenta praevia after prostaglandin-induced abortion, and the multigravidae in that group had a longer average duration of labour than the control group. Sixty-five per cent of the post-abortion pregnancies were unplanned compared with $36 \%$ of the control group.

\section{Introduction}

The annual number of therapeutic abortions performed in England and Wales reached a peak in 1973 and has since declined $^{1}$; the number of abortions performed during the second trimester has proportionately fallen since the Abortion Act 
(1967) was passed, but continues to account for approximately $20^{\circ}{ }_{0}$ of the total. ${ }^{2}$ In many gynaecological units the administration of prostaglandins, especially by intrauterine instillation, has become the most acceptable and efficient method of managing the latter. Recent reports show that their use for this purpose is associated with a low incidence of immediate complications and delayed morbidity..$^{3-5}$

Data on the possible effects of previous prostaglandininduced abortions on future pregnancies are, however, lacking. To assess the magnitude of such problems we performed a prospective survey during the first five years of prostaglandin usage for pregnancy termination in Oxford.

\section{Patients and methods}

We traced a total of 204 pregnancies (index pregnancies) reported by 168 patients by a continuous long-term follow-up survey. Postal questionnaires were sent to more than 850 women at least 18 months after a prostaglandin-induced abortion ${ }^{5} ; 588$ completed questionnaires were received; 420 patients reported no further pregnancy since termination. Personal consent for this investigation had been obtained during initial admission. Analysis of features of the patients for whom follow-up questionnaires were not available showed that the sample studied was representative of the total population to whom questionnaires were sent with regard to age, marital state and parity, and gestation at the time of abortion. We scrutinised relevant hospital records for details of the subsequent pregnancies or requested assistance from the attending doctor if the pregnancy was managed outside Oxford.

We analysed details of the initial prostaglandin-induced abortions. The period of gestation at which the original abortion was performed and the route of prostaglandin administration are shown in table I;

TABLE I-Details of initial prostaglandin-induced abortion in 168 women

\begin{tabular}{|c|c|c|c|c|}
\hline \multirow{2}{*}{ Route of administration } & \multicolumn{3}{|c|}{ Gestation (weeks) } & \multirow{2}{*}{ Tota } \\
\hline & -12 & $13-19$ & 20 & \\
\hline 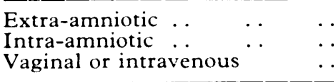 & 14 & $\begin{array}{r}112 \\
18 \\
7\end{array}$ & $\begin{array}{r}12 \\
5\end{array}$ & $\begin{array}{c}138^{*} \\
23 \\
7\end{array}$ \\
\hline Total & 14 & 137 & 17 & $168^{+}$ \\
\hline
\end{tabular}

*Includes 22 missed abortions between 10 and 24 weeks' gestational size.

+ Protaglandin $E_{2}(n=129)$; prostaglandin $F_{2} \alpha$ or analogue $(n=39)$.

35 pregnancies occurred in 25 women whose original therapeutic abortion was performed for eugenic reasons or to evacuate a missed abortion. Post-abortion surgical evacuation was performed in 76 of the 168 patients $(45.2 \%)$ when 73 of them were single, 85 married, and 10 separated, divorced, or widowed. The techniques of prostaglandin administration have been described elsewhere ${ }^{6-9} ; 129$ patients were given prostaglandin $\mathrm{E}_{2}\left(\mathrm{PGE}_{2}\right)$ and 39 prostaglandin $\mathrm{F}_{2} \alpha\left(\mathrm{PGF}_{2} \alpha\right)$ or an analogue.

Controls were 612 women consecutively admitted to the obstetrical and gynaecological departments in Oxford during a six-week period in 1976 for delivery or spontaneous or induced abortions (see table II). Only patients with a history of previous therapeutic abortions were excluded from the control group. When possible we assessed whether the pregnancy was planned from the response to direct questioning recorded in the patient's hospital records.

\section{Results}

Of the 204 index pregnancies, 171 were managed in the Oxford obstetrical and gynaecological units. One hundred and thirty-eight women had had one subsequent pregnancy, 24 two pregnancies, and six three pregnancies. The mean $(t$ standard error of mean) interval between abortion and first subsequent conception was 10.4 \pm 0.6 months, and 112 patients $(66.7 \%)$ had conceived within 12 months of the prostaglandin-induced abortion. No secondary subfertility was reported by any of the 168 patients.

Table III shows the outcome of the 204 index pregnancies and the
TABLE II-Marital state, age, social class, and parity of women at the time of index and control pregnancies. Figures are numbers (\%) of women

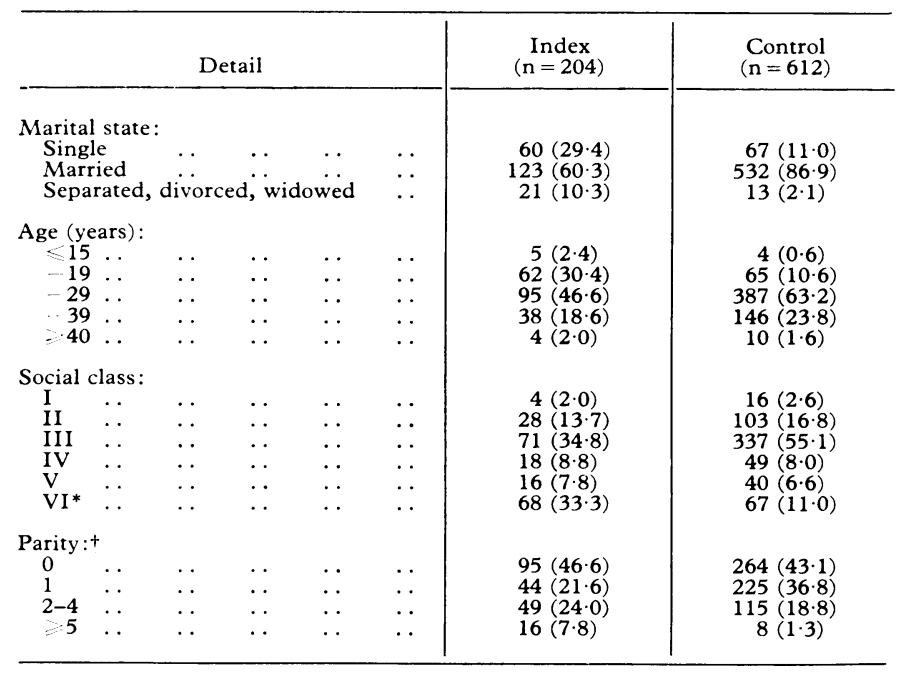

*Unemployed or social class unspecified.

†Previous pregnancies of more than 28 weeks' gestation.

TABLE III-Outcome of 204 index pregnancies and 612 control pregnancies

\begin{tabular}{|c|c|c|c|c|c|}
\hline \multicolumn{4}{|c|}{ Outcome } & Index $\left({ }^{0}{ }_{0}\right)$ & Control $(\%)$ \\
\hline \multicolumn{2}{|l|}{$\begin{array}{l}\text { Term deliveries } \\
\text { Spontaneous abortion: }\end{array}$} & . & .. & $127(62 \cdot 2)$ & $482(78 \cdot 7)$ \\
\hline First trimester & .. & .. & $\cdots$ & $12(5.9)$ & $30(4 \cdot 9)$ \\
\hline Second trimester & .. & .. & . & $7(3.4)$ & $9(1.5)$ \\
\hline Missed $\quad \ldots$ & .. & .. & . & $1(0.5)$ & $2(0.3)$ \\
\hline $\begin{array}{c}\text { Ectopic } \\
.\end{array}$ & . & .. & $\cdots$ & $2(1.0)$ & $4(0 \cdot 6)$ \\
\hline $\begin{array}{l}\text { 1nduced abortion: } \\
\text { First trimester }\end{array}$ & .. & .. & & $32(15 \cdot 7)$ & $61(10.0)$ \\
\hline Second trimester & $\because$ & $\because$ & $\because$ & $23(11 \cdot 3)$ & \\
\hline Total $\ldots \quad \ldots$ & $\therefore$ & .. & .. & $204(100)$ & $612(100)$ \\
\hline
\end{tabular}

612 control pregnancies analysed. Of the patients for whom data were available, $65 \%$ (126 of 194 pregnancies) of the former group were unplanned, compared with $36 \%$ (196 of 546 pregnancies) of the latter.

\section{TERM PREGNANCIES}

We analysed 127 pregnancies, including two multiple pregnancies, in the index group, and 482 , including four multiple pregnancies, in controls. Table IV shows the mean values $( \pm S E M)$ for gestation at delivery, duration of labour, and infant birth weight of the singleton pregnancies for the two groups. The only significant difference $(\mathrm{P}<0.01 ; t$ test $)$ between the two groups was the mean duration of labour in multigravidae.

Table $\mathrm{V}$ shows the morbidity features for the term pregnancies in the two groups. Spontaneous preterm labour and delivery (before 37 weeks) occurred in three pregnancies $(2.4 \%)$ in the index group and $19(3.9 \%)$ in the control group. The former figure is derived from one patient with placental insufficiency delivered at 36 weeks'

TABLE IV-Mean values ( \pm standard error of mean) for gestational age, duration of labour, and infant birth weight in singleton term pregnancies in index and control groups

\begin{tabular}{|c|c|c|c|c|c|}
\hline \multicolumn{4}{|c|}{ Variable } & Index $(n=125)$ & Control $(n=478)$ \\
\hline $\begin{array}{c}\text { Gestation at delive } \\
\text { All patients } \ldots \\
\text { Primigravidae } \\
\text { Multigravidae }\end{array}$ & $\begin{array}{l}\text { (we } \\
\cdots \\
\cdots \\
\cdots\end{array}$ & $\begin{array}{l}: \\
\cdots \\
\cdots\end{array}$ & $\begin{array}{l}\cdots \\
\cdots\end{array}$ & $\begin{array}{l}39.46 \pm 0.20 \\
39.61 \pm 0.20 \\
39.30 \pm 0.19\end{array}$ & $\begin{array}{l}39.46 \pm 0.12 \\
39.51 \pm 0.16 \\
39.43 \pm 0.10\end{array}$ \\
\hline $\begin{array}{c}\text { Duration of labou } \\
\text { All patients } \\
\text { Primigravidae } \\
\text { Multigravidae }\end{array}$ & $\begin{array}{l}\text { our } \\
\cdots \\
\cdots \\
\cdots\end{array}$ & $\begin{array}{l}\cdots \\
\cdots\end{array}$ & $\begin{array}{l}\cdots \\
\cdots\end{array}$ & $\begin{array}{r}8.93 \pm 0.75 \\
10.24 \pm 0.77 \\
7.42 \pm 0.72\end{array}$ & $\begin{array}{l}7.42 \pm 0.28 \\
9.66 \pm 0.37 \\
5.81 \pm 0.22\end{array}$ \\
\hline $\begin{array}{c}\text { Infant birth weigh } \\
\text { All patients } . . \\
\text { Primigravidae } \\
\text { Multigravidae }\end{array}$ & $\begin{array}{l}\text { g): } \\
\cdots \\
\cdots\end{array}$ & $\begin{array}{l}\because \\
\cdots\end{array}$ & $\begin{array}{l}\ldots \\
\cdots\end{array}$ & $\begin{array}{l}3311 \pm 70 \cdot 0 \\
3287 \pm 64 \cdot 7 \\
3338 \pm 75 \cdot 9\end{array}$ & $\begin{array}{l}3290 \pm 36 \cdot 7 \\
3235 \pm 47 \cdot 1 \\
3329 \pm 29 \cdot 3\end{array}$ \\
\hline
\end{tabular}


gestation and an unmarried teenage girl who had had no antenatal care, and laboured in successive pregnancies at 33 and 36 weeks' gestation respectively. In neither group was there any precipitate labour or delivery. Each of the three patients in the index group with prophylactic Shirodkar sutures had the stitch removed at 38 weeks' gestation, and labour had to be induced five and 10 days and three weeks later, respectively.

TABLE $\mathrm{V}-$ Morbidity of 127 index term pregnancies and 482 control term pregnancies. Figures are numbers $\left({ }_{0}^{\circ}\right)$ of total pregnancies in each group

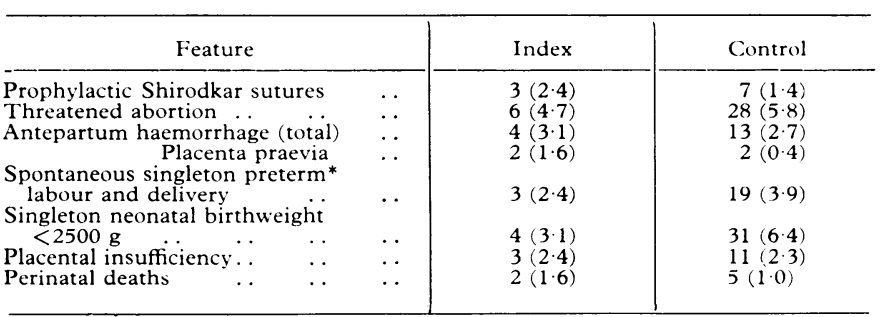

*Labour or delivery at less than 37 weeks' gestation.

Four of the singleton neonates in the index pregnancy group weighed less than $2500 \mathrm{~g}$ at birth - two were preterm, and two were growth-retarded; this compared with 25 and six respectively in the control pregnancy group. There was one unexplained stillbirth of undetermined gestation and one stillborn anencephalic fetus at 30 weeks' gestation among the index pregnancies, compared with three fresh stillbirths and two neonatal deaths in the control group. Apart from the stillborn anencephalic fetus no other congenitally abnormal fetus was delivered in the index pregnancy group; in the control group three neonates had major congenital abnormalities. Four infants in the index group were adopted and one of the two sets of twins were battered babies at three months of age; one infant in the control group was adopted.

There was no apparent relation between the above features in the index pregnancies and the period of gestation at which the original prostaglandin-induced abortion had been performed, the route of prostaglandin administration, the interval between induction and abortion, and the need for post-abortion surgical evacuation.

\section{SPONTANEOUS ABORTION}

Spontaneous miscarriage occurred in 19 of the $204\left(9.3^{\circ}\right)$ index pregnancies compared with 39 of the $612(6.4 \%)$ control pregnancies (see table III); this difference was not significant $\left(\gamma^{2}\right.$ test). Nevertheless, if all pregnancies that were therapeutically terminated or were ectopic gestations are excluded, the incidence of spontaneous abortion in the two groups (20/147 and 41/523 respectively) is significantly different $\left(P<0.05 ; \chi^{2}\right.$ test). When analysed separately, however, the incidences of spontaneous first-trimester abortion in the index and control groups and of second-trimester abortions in the two groups are not significantly different. Of the 168 first subsequent index pregnancies, $15(8.9 \%)$ spontaneously aborted.

Seven spontaneous second trimester abortions between 16 and 26 weeks' gestation occurred in six patients; one patient miscarried twice at 19 and 23 weeks' gestation respectively without evidence of cervical incompetence, and has yet to have a successful pregnancy. One patient aborted at 24 weeks, after seven days' abdominal pains with no clinical evidence of cervical incompetence, and one patient aborted at 19 weeks' gestation, two weeks after diagnostic amniocentesis and subsequent ruptured membranes. One patient aborted triplets at 26 weeks' gestation, having had a prophylactic Shirodkar suture inserted three days previously, and one grand multiparous patient aborted at 16 weeks. The final patient aborted at 23 weeks' gestation with clinical evidence of cervical incompetence; her first pregnancy had been terminated at 14 weeks' gestation by vaginal aspiration, and a subsequent uncomplicated term pregnancy resulted with the aid of a Shirodkar suture (see above).

The patient who had a missed abortion at 20 weeks' gestation and one of the patients with an ectopic pregnancy subsequently had uncomplicated term pregnancies. Eight of the 12 spontaneous firsttrimester abortions were followed by uncomplicated term pregnancies.

Analysis of the small number of spontaneous first- and second- trimester abortions does not indicate any specific association with the management of the previous prostaglandin-induced abortion.

\section{THERAPEUTIC ABORTION}

Fifty-five $\left(27 \cdot 0^{\circ}{ }_{0}\right)$ of the 204 index pregnancies were terminated; three patients have had two subsequent therapeutic abortions. Twenty-four of the patients were still single, 22 married, six separated, and 16 under 20 years of age when their pregnancies were terminated the second time. Thirty-two repeat abortions were performed during the first trimester, 18 by vaginal aspiration, 11 using prostaglandins, and three by hysterectomy. The remaining 23 pregnancies were terminated in the second trimester using intrauterine prostaglandins.

In the control group there were $85\left(13.9^{\circ}\right.$ o $)$ therapeutic abortions, 61 in the first trimester (by vaginal aspiration or early prostaglandin treatment) and 24 in the second trimester (using intrauterine prostaglandins).

\section{Discussion}

Many reports have highlighted the increased morbidity associated with abortion performed surgically during the second trimester; such morbidity appears to be reduced when prostaglandins are used. $^{3}$ The possible effects of prostaglandininduced abortion in the second trimester on the outcome of subsequent pregnancies must, however, be assessed.

A study of this nature is of greater value if the results can be compared with a control group, but a dilemma arises as to the composition of the controls. ${ }^{10}$ There are arguments for selecting nulliparous primigravidae as controls for women having their first pregnancy terminated. Equally it has been suggested that women who have had a previous spontaneous abortion should be chosen, ${ }^{112}$ or even that women who have had one previous term delivery might be more appropriate. ${ }^{13}$ In view of this unresolved dilemma, we chose the control group from women consecutively admitted to hospital for delivery or abortion, both induced and spontaneous; women with a history of previous therapeutic abortion were excluded. We made no attempts to match for other compounding maternal factors.

There was no significant difference in morbidity between the index and the control pregnancies. This is particularly important as the former group contained more unmarried and "separated" women of lower social class and more primiparous and grand multiparous women than the control group; all such factors have been shown adversely to affect the outcome of pregnancy. ${ }^{14} \mathrm{~A}$ similar study from Taiwan ${ }^{10}$ of termination by uterine curettage illustrated the effect that these compounding maternal factors may have upon the results of such a study. Of relevance also is the similarity in the outcome of the present index group to the series studied by Vessey and Doll, ${ }^{15}$ consisting of women with unplanned pregnancies after failed contraception.

Our results show that abortion induced during the second trimester with prostaglandins does not increase the incidence of preterm labour. The incidence of placental insufficiency and placental abruption, both of which have been suggested to occur more often after induced abortion, was not increased. There was also no evidence that the birthweight of subsequent infants was affected by previous abortion. The occurrence of two cases of placenta praevia requiring caesarean section $\left(1 \cdot 6^{\circ}{ }_{0}\right)$ represents an increased incidence, four times that of the control group; numbers are small, but this figure does indicate the need to be watchful for this particular problem.

The occurrence of $19\left(9 \cdot 3^{\circ}{ }_{0}\right)$ spontaneous miscarriages in the index group compared with $39\left(6 \cdot 4^{\prime \prime}{ }_{1}\right)$ in the control group suggests a slightly increased tendency in the former, which reaches statistical significance when terminated and ectopic pregnancies are excluded. The incidence of ectopic pregnancies in the index group $\left(1^{\circ}{ }_{0}\right)$ was greater than that observed in the control group $\left(0 \cdot 6^{\circ}\right)$, but well below the tenfold increased 
incidence after induced abortion reported by Panayoti et al. ${ }^{16}$ Possibly the slightly raised rate in the present study might be related to the contraceptive method used after termination and before subsequent conception. ${ }^{1.5}$ Of particular importance is the number of spontaneous second-trimester abortions. Cervical incompetence resulting from induced abortion by vaginal aspiration has been a cause for concern. ${ }^{11} 12 \mathrm{~A}$ recent investigation has shown that cervical dilatation beyond $12 \mathrm{~mm}$ at termination by vaginal aspiration is associated with enlarged cervical canal diameters and possible loss of cervical integrity. ${ }^{17}$ Similar concern for cervical incompetence after prostaglandininduced abortion has been expressed, and routine prophylactic suturing of the cervix is advocated in such cases. ${ }^{\text {" }}$ Our evidence suggests that such radical management is not justified. In the present series only one abortion in the index group may have been due to cervical incompetence, possibly resulting from an initial termination by vaginal aspiration at 14 weeks' gestation. More sinister, and probably important, however, is the occurrence of cervicovaginal fistulae after prostaglandin-induced abortion..$^{19}$ The precise aetiology of these lesions is at present obscure" "; the prostaglandin used for the abortion has been implicated, but this theory has been recently dismissed." 1

None of our patients reported subfertility, and none was found in a survey assessing delayed morbidity ; we acknowledge, however, that we have only been able to study the fertility of a limited percentage of the total numbers undergoing a prostaglandin-induced abortion. Nevertheless, the incidence of unplanned subsequent pregnancies in the index group $\left(65^{\circ}{ }_{11}\right)$ is disturbingly high compared with the control group $\left(36^{\circ}{ }^{\prime}\right)$. We analysed these patients' details, and found that unmarried teenage patients of the lower social class are at special risk. Further, there was a larger proportion of therapeutic abortions in the second trimester in the index group than the control group, suggesting that the previous induction of abortion with prostaglandin-probably more unpleasant than a surgical aspiration under anaesthetic-is no deterrent. Apparently the challenge of the conscientious use of effective contraception is still greater than the fear of a further therapeutic abortion.
We thank Ms Jean Fedrick and Mr M P Embrey for advice and criticism on the preparation of this paper; the consultant staff in Oxford for allowing us access to the notes of patients admitted under their care; and the medical practitioners. who so readily assisted with details of patients who were managed outside Oxford. Part of this work was supported by a grant from the World Health Organisation.

\section{References}

${ }^{1}$ Department of Health and Social Security, On the State of the Public Health for the year 1975, p 64. London, HMSO, 1976.

2 Registrar General's Statistical Review of England and Wales for 1973, supplement on Abortion, p 9. London, HMSO, 1974.

3 MacKenzie, I Z, Hillier, K, and Embrey, M P, British Medical fournal, $1974,4,683$

' Kajanoja, P, et al, Acta Obstetricia et Gynecologica Scandinavica, 1975, suppl $37,51$.

${ }^{5}$ MacKenzie, I Z, and Hillier, K, International fournal of Gynecology and Obstetrics, 1975, 13, 209.

${ }^{6}$ Embrey, M P, British Medical fournal, 1970, 2, 258

'Embrey, M P, Hillier, K, and Mahendran, P, Advances in Biosciences, 1973, 9, 507

${ }^{8}$ MacKenzie, I Z, Embrey, M P, and Hillier, K, fournal of Obstetrics and Gynaecology of the British Commonwealth, 1974, 81, 554.

${ }^{9}$ MacKenzie, I Z, and Embrey, M P, British fournal of Obstetrics and Gynaecology, 1976, 83, 505.

10 Daling, J R, and Emanuel, I, Lancet, 1975, 2, 170.

1 Wright, C S W, Campbell, S, and Beazley, J, Lancet, 1972, 1, 1278.

${ }^{12}$ Richardson, J A, and Dixon, G, British Medical fournal, 1976, 1, 1303.

${ }_{13}$ Trussell, J, British fournal of Hospital Medicine, 1973, 9, 601.

${ }^{14}$ Butler, N R, and Bonham, D G, Perinatal Mortality, p 14. London, Livingstone, 1973.

${ }_{15}$ Vessey, M P, and Doll, R, Proceedings of the Royal Society. Series B. Biological Sciences, 1976, 195, 69.

16 Panayoti, P P, et al, American fournal of Obstetrics and Gynecology, 1972, 114, 507.

1: Johnstone, F D, et al, British Medical fournal, 1976, 1, 68.

${ }_{18}$ Murray, J, Medical fournal of Australia, 1974, 2, 717.

19 Kajanoja, P, et al, Fournal of Obstetrics and Gynaecology of the British Commonwealth, 1974, 81, 242.

20 MacKenzie, I Z, and Hillier, K, British Medical fournal, 1974, 4, 405.

${ }^{21}$ MacKenzie, I Z, British Fournal of Obstetrics and Gynaecology, 1976, 83, 780 .

(Accepted 24 August 1977)

\title{
Should the indications for prenatal chromosome analysis be changed?
}

\author{
JOHN PHILIP, JENS BANG, METTE MADSEN
}

British Medical fournal, 1977, 2, 1117-1119

\section{Summary}

Amniocentesis for chromosome analysis was performed in 1086 pregnant women, 739 of whom had an increased risk of giving birth to a child with chromosome abnormalities. Such abnormalities were found in almost iden-

\footnotetext{
Department of Obstetrics and Gynaecology YA, Righospitalet, University of Copenhagen, Copenhagen

JOHN PHILIP, MD, professor of gynaecology

Department of Obstetrics, St Joseph's Hospital, Copenhagen JENS BANG, MD, head of department

tical proportions among the fetuses with an increased risk $(1.2 \%)$ and among those with no increased risk $(1.4 \%)$. Findings in several other studies seem to confirm that there is no significant difference between the risk groups in the proportion of abnormalities found.

This suggests that our current risk groups may not be the right ones, but a much larger study is needed to confirm this.

\section{Introduction}

Prenatal chromosome analysis is now considered to be part of routine prenatal care in many obstetric departments. Investigation is usually offered to women with a known increased risk of having a child with a chromosome abnormality. The child is recognised to be at risk when $(a)$ one of the parents has a balanced translocation or is a mosaic; (b) the mother is over 35 (or 40) years; or (c) the mother has given birth to a child with a chromosome abnormality. Furthermore, families with serious X-linked 